\title{
Key success factors of strategic management implementation in SMEs in Iran
}

\author{
Shahin Pournasir \\ Coventry University, $U K$ \\ gama.epage@gmail.com
}

Abstract. Strategic management is a sub-discipline of filament of management which includes a variety of methods and disciplines; furthermore, it evolves both quantities and behavioral sciences that make strategic management art and science (David. F 2005; Parnell, 2005). In addition to that, the most important objective of the strategic management procedure is to help businesses to be successful by making themselves distinctive in a competitive way from other businesses and by giving them the chance to capitalize on their inner strengths and exterior chances while reducing their inner weaknesses and exterior threats (Bryson, 1995; David. F2005; Porter, 1985; Steiner, 1976). Furthermore, one of the major functions of the Strategic Management is to help the managements in their choosing process when they need to pick up between different options (Parnell 2005, Porter 1985). Higgins and Vincze (1993) state that, "Strategic management is the process of administration the pursuit of organizations mission while managing the relationship of the organization to its environment". Moreover, nowadays small and medium enterprises (SMEs) have critical role on the world economy and employee rate of countries as a result policy makers and governments attempt to make better environment to attract entrepreneurs and investors to establish SMEs business. In this regards, the purpose of this research is to investigate and evaluate the key success factors (KSFs) of Strategic Management implementation in SMEs in the Iran. Also a comparison was conducted with other researches in field of strategic Implementation in developed and developing countries, in order to establish a recommendation and framework to have successful Strategic implementation in SMEs in the Iran.

Keywords: Strategic Management, Strategic Implementation, KSFs of strategic Implementation, SMEs, IRAN.

JEL classification: L10, M11. 


\section{INTRODUCTION}

Strategic management is very broad field and it can be defined in many ways. In addition, this topic involves other management tools and techniques such as scientific management and risk management (Stoney. C, 2001).

The origin of strategic management originated from strategy, which in the simplest concept considered as a consolidate idea that links purpose and action (White. C, 2004). The beginning of strategic management dates backs to as early as 19th century when Henry Fayola suggests that "the planning should be use as a technique to improve the effectiveness of firm's performance", Likewise, Wilson and Essien (2012) state that, strategic management is a" process of formulating, implementing, and evaluating, strategies to achieve long-term goals and sustain competitive advantages". Thus, in the current competitive and economic world, many companies use strategic management as a significant structure to make the business environment more manageable (Hunger and Wheelen 2008). In order to implement the defined strategy effectively and to enhance the growth of the company, the strategic decisions should be taken in a faster way and the response should be high (Joyce and Woods 2003). Moreover, many researchers state that one of the most reasons for having an unsuccessful strategic management refers to the failure of implementing the strategy.

\section{LITERATURE REVIEW}

Strategic management is a sub-discipline of filament of management which includes a variety of methods and disciplines; furthermore, it evolves both quantities and behavioral sciences that make strategic management art and science (David, 2005; Parnell, 2005). In addition to that, the most important objective of the strategic management procedure is to help businesses to be successful by making themselves distinctive in a competitive way from other businesses and by giving them the chance to capitalize on their inner strengths and exterior chances while reducing their inner weaknesses and exterior threats (Bryson, 1995; David, 2005; Porter, 1985; Steiner, 1996). Furthermore, one of the major functions of the Strategic Management is to help the managements in their choosing process when they need to pick up between different options (Parnell 2005, Porter 1985). Higgins and Vincze (1993) state that, "Strategic management is the process of administration the pursuit of organizations mission while managing the relationship of the organization to its environment".

Moreover, strategic management effectively discusses four points and it gives answers for these points in order to understand the business clearly (Wheelen and Hunger 2008). Strategic management function and definition they are as follow (Hofstrand 2007):

- The current position of the business.

- The position of the business in the future (Target).

- The way to reach that position (Strategy of firms to achieve to target).

- The new position situation (evaluation and feedback)

- The fundamental model of strategic management is consist of four phases which illustrate as follow, additionally each phases has their sub-phases and element. 


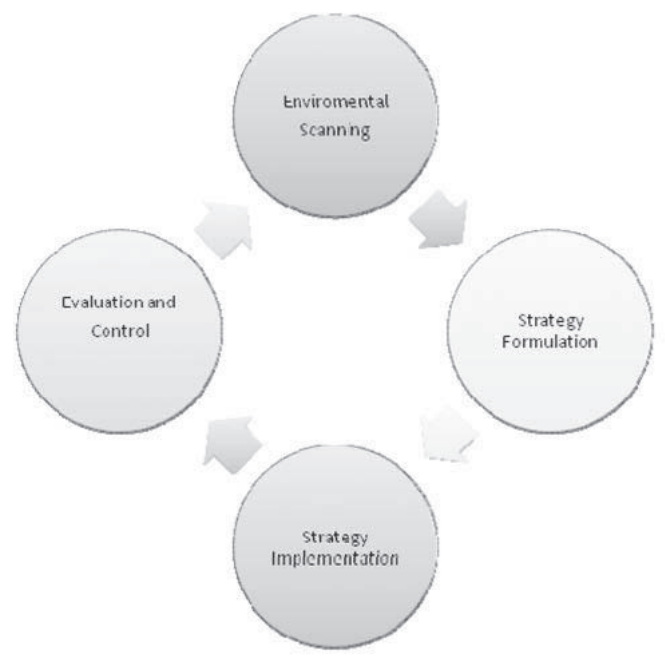

Figure 1: Strategic management phases (Wheelen and Hunger 2008)

In this respect, strategic implementation is the process of translating the strategic formulation into positive actions by establishing programs, determining budgets, and creating procedures. In addition to that, implementation is a key in the strategic management process, it is the last step in the strategic management process and it comes after the strategy has been formulated (Waters, Donald and Waters 2006). In general, strategy formulation and strategy implementation are assumed as two sides of the same coin (Wheelen and Hunger 2008).

Furthermore the strategy implementation can be defined in different ways that this variety shows several diverse concepts of strategy implementation.

- The first definition refers to Aaker (1998) views about implementation that he stated; the implementation phase included converting "strategic alternative" into an operational plan.

- "Implementation is the managerial intervention that align organizational action with strategic intended" (Floyd and Woolridge, 1992).

- Cespedes (1991) defines implementation in simple ways as "how-to-do-it" feature of marketing.

Moreover, as a significant of strategic management, many authors and researchers for decades attempt to identify and evaluate the factors which have influence on strategic management implementation. In this respect, brief summary of related works are illustrated in table (1).

Table 1

Factors influencing strategy implementation (KЦSEO LU.M et al, 2009)

\begin{tabular}{|l|l|}
\hline \multicolumn{1}{|c|}{ Researcher/Authors } & \multicolumn{1}{c|}{ Factors/ Element } \\
\hline \multicolumn{1}{|c|}{1} & \multicolumn{1}{c|}{2} \\
\hline David (1987) & Motivation, leadership and direction skills, co-ordination \\
\hline Skivington\& Daft (1991) & Intended strategy, structure, systems, interactions, sanctions \\
\hline Roth et al (1991) & $\begin{array}{l}\text { Coordination, managerial philosophy, configuration, formalization, centralization, } \\
\text { integrating mechanisms }\end{array}$ \\
\hline
\end{tabular}




\begin{tabular}{|l|l|}
\hline \multicolumn{1}{|c|}{1} & \multicolumn{1}{c|}{ 2 } \\
\hline Yip (1992) & Organizational structure, culture, people, managerial processes \\
\hline $\begin{array}{l}\text { Bryson \&Bromiley } \\
(1993)\end{array}$ & Context, process, outcome \\
\hline $\begin{array}{l}\text { Lingle\&Schieman } \\
(1994)\end{array}$ & $\begin{array}{l}\text { Market, people, finance, operation, adaptability, and environmental } \\
\text { Factors }\end{array}$ \\
\hline Okumus (2001) & Content, context, process, outcome \\
\hline Higgins (2005) 8's & $\begin{array}{l}\text { Strategy and purposes, structure, systems and processes, style of leadership, staff, } \\
\text { resources, shared values, organizational culture, and strategic Performance. }\end{array}$ \\
\hline Birnbaum (2007) & $\begin{array}{l}\text { Action planning; organizational structure; human resources; the annual business } \\
\text { plan; monitoring and control; the linkage- The Foundation for Everything Else. }\end{array}$ \\
\hline
\end{tabular}

Furthermore, Alashloo et al. (2005) attempts to categorize the factors which lead to failure or make obstacle of strategies under four main headings:

- Planning Consequences,

- Organizational Issues

- Managerial Issues,

- Individual issues.

However, Alashloo et al. (2005) does not deal with the question of which of these categories has greater influence on the failure or success of strategies.

\section{METHODOLOGY}

This research applied mixed methods strategy which involved questionnaire as qualitative and interview as qualitative methods. In order to collect the required data and information with highest quality, in phase of quantitative methods the open-ended questioner sent to member of Industrial managers association (Society of Industry Leaders) and entrepreneurs.Also the author in phase of qualitative had semi- structure interviews with high level employee of two companies and 12 entrepreneurs which in first section of interview there wasnot a formal question, and candidate and researcher had informal chatting in order to implementation of strategic management and management in general. In the second section the conductors of this research asking the similar question with questioner.

Furthermore, rational of author to choose the mixed strategy can be following as:

- Complementarily, is one of the main reasons for the researcher to choose mixed strategy that led to illustration, enhancement, elaboration, enhancement and clarification of the final outcome by comparing it with the output received from another method

- Initiation, second reason for choosing mixed strategy refers to identify and detection of possible conflict and paradox in the result also discovery of a new viewpoint and perspective of structure or framework.

\section{RESEARCH POPULATION}

This research has been conducted about small and medium enterprises (SMEs) in the Iran for manufacturing industries. Moreover, in order to achieve the research aims and objectives, the population of research has been chosen from senior managers, Chief executive and entrepreneurs of the Iran. 


\section{SAMPLING}

The sample size of this research in questionnaire as quantitative method was 113 which about $88 \%$ of respondents answer all question, however 49 respond qualified in process because some because of excluding large- size enterprises and inappropriate responds.

Moreover,the sample size of this research in interview as a qualitative method was 20 which participant selected for this particular research had in-depth expertise in strategic management implementation and have more than 20 years' work experience.

\section{RESULT}

The present survey aimed to find out the Key success factors of executing the strategic management implementation in SMEs in Iran. In this respect, to have comprehensive analysis and evaluation of KSFs the researcher additionally identified and evaluated the factors which lead to failure of strategic management implementation or make obstacle of strategic management.

\section{PART ONE: QUANTITATIVE ANALYSIS}

\section{SECTION ONE: KSFS}

\section{Most important Factor}

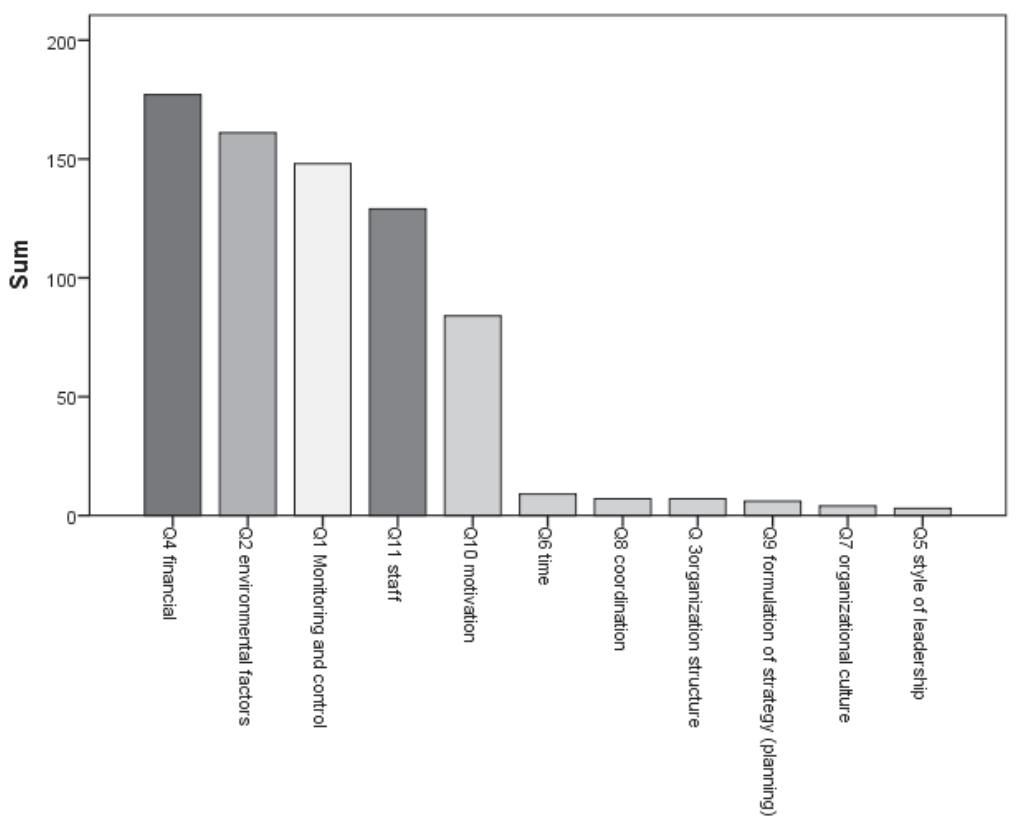

Figure 2. KSFs 
Figuretwoverify that, the most important factor which has significant role to have successful strategic implementation in SMEs in Iran is financial resources (budget), on the other word, without sufficient financial resources the enterprise cannot implement their strategy successfully. In addition, Lingle\&Schieman(1994) classified the financial recourses as a factor which has influence on strategy implementation towards the success. Furthermore, Strouhal et al, 2009 state that: the financial issue can be categorised as weakest point of SMEs, thus it canbe concluded if Small and medium enterprises has capability to cope with financial issue the percentage of have successful strategic management implementation will be rise dramatically.

Although table 3 illustrate that, the financial factor has the highest mean between five KSFs, However, 44 form 49 participants considered, financial issue as a one of Key success factor (KSFs) of Strategic Management implementation in SMEs in Iran thus financial factors is pervasive factors but is not most pervasive factors.

Table 2

Descriptive satistic of SKSFs

\begin{tabular}{|l|c|c|c|c|c|}
\hline \multicolumn{7}{|c|}{ Descriptive Statistics } \\
\hline & $\mathrm{N}$ & Minimum & Maximum & Mean & Std. Deviation \\
\hline Q1 monitoring and control & 47 & 1 & 5 & 3.15 & 1.161 \\
\hline Q2 environmental factors & 47 & 1 & 5 & 3.43 & 1.211 \\
\hline Q 3 organization structure & 3 & 1 & 4 & 2.33 & 1.528 \\
\hline Q4 financial resources & 44 & 1 & 5 & 4.02 & 1.110 \\
\hline Q5 style of leadership & 3 & 1 & 1 & 1.00 & .000 \\
\hline Q6 time & 2 & 4 & 5 & 4.50 & .707 \\
\hline Q7 organizational culture & 1 & 4 & 4 & 4.00 & .408 \\
\hline Q8 coordination & 6 & 1 & 2 & 1.17 & 2.828 \\
\hline Q9 formulation of strategy & 2 & 1 & 5 & 3.00 & 1.379 \\
\hline Q10 motivation & 43 & 1 & 5 & 1.95 & 1.224 \\
\hline Q11 staff & 47 & 1 & 5 & 2.74 & \\
\hline
\end{tabular}

\section{Second Most Important Factor}

The second most important factors to SMEs in Iran towards have successful strategic management implementation is Environmental factors, in this respect, according to the outcome of SWOT and PEST analysis of Industry analysis, one of the main threats of SMEs is lack of capability to cope with environmental changes such as economic crises, so it can be conclude, the result of SWOT analysis support the result of questionnaires in this particular question. In addition, Lingle\&Schieman(1994) classified the environment as a factor which has influence on successful strategy implementation.

Moreover, figure one shows that, environmental factors with monitoring and control and staff are most pervasive factors, ( $470 \mathrm{f} 49$ participants has chosen those factors as one of the KSFs). Additionally this factor has a second highest mean between the five most important KSFs of SMEs in Iran.

Concluding, this result proves the importance of Environmental scanning as first step in Wheelen and Hunger (2000) model of Strategic management. 


\section{Third Most Important Factor}

Monitoring and control is a Third most important factors to have successful implementation of strategic management in Small and medium enterprises in Iran. Additionally, as a table five illustrate, monitoring and control has a one of the highest pervasive factors among participants (47 out of 49 participants).In addition, this outcome proves the significance of the last steps in Wheelen and Hunger Model of strategic management. Furthermore, in this respect, Birnbaum (2007) classify Monitoring and control as one of KFSs strategy implementation.

\section{Fourth and Fifths Most Important Factor}

Figure one indicate that the staff and motivation have the fourth and fifth greatest rank in viewpoint of participants in this questionnaire in order to KSFs of strategic Management implementation in SMEs in Iran.

Furthermore, according to table 3 staff has a one of the greatest pervasive factors among participants but the motivation has lowest pervasive factorsin Five most important factors among therespondents of this questionnaire.

Although, Yip (1992) andLingle\&Schieman (1994) in their research include the staff as factors has influence on influence on KFSs strategy implementation. Additionally, David (1987) classifies the motivation as a factor which has influence on KFSs strategy implementation.

\section{SECTION TWO: PITFALLS AND BARRIERS}

In this section of survey, the researcher applied Alashloo et al. (2005) categorization as foundation of his work in order to classify factors which lead to failure or make obstacle of strategies under four main headings.

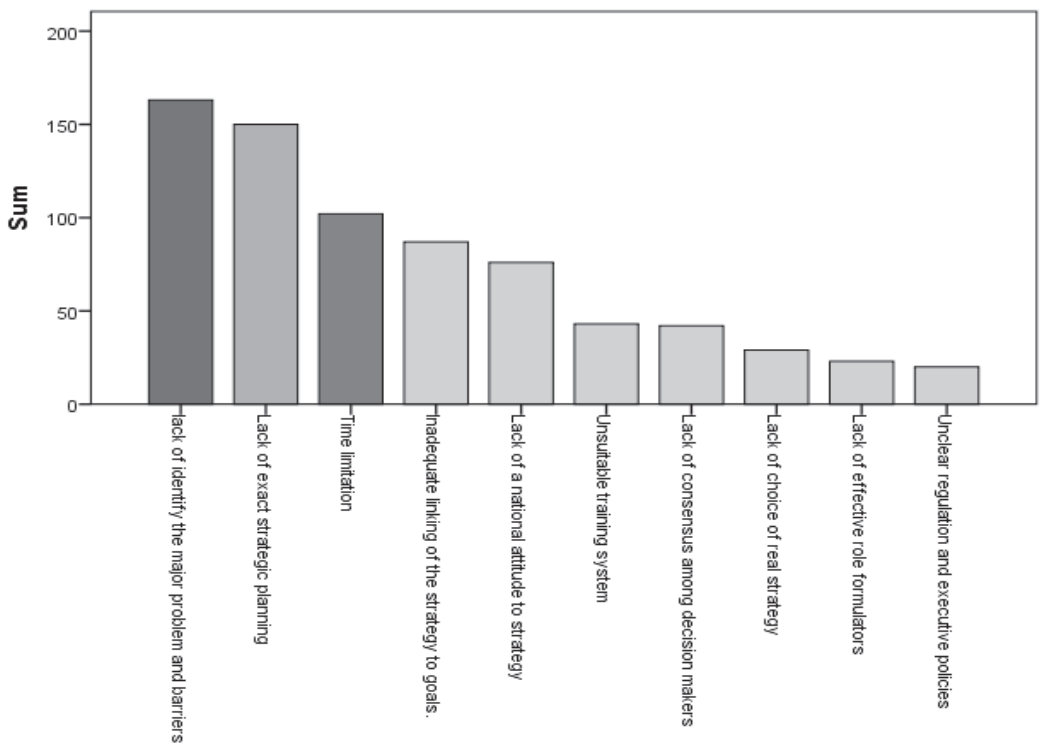

Figure 3. Barriers in field of Planning 
Table 3

Descriptive Statisticsof barriers in planning section

\begin{tabular}{|c|c|c|c|c|c|}
\hline \multicolumn{6}{|c|}{ Descriptive Statistics } \\
\hline & $\mathrm{N}$ & Minimum & Maximum & Mean & Std. Deviation \\
\hline Lack of exact strategic planning & 44 & 1 & 5 & 3.41 & 1.085 \\
\hline $\begin{array}{l}\text { Inadequate linking of the strategy to } \\
\text { goals. }\end{array}$ & 42 & 1 & 5 & 2.07 & 1.177 \\
\hline Time limitation & 43 & 1 & 5 & 2.37 & 1.176 \\
\hline $\begin{array}{l}\text { Lack of consensus among decision } \\
\text { makers }\end{array}$ & 10 & 3 & 5 & 4.20 & .632 \\
\hline $\begin{array}{l}\text { lack of identify the major problem and } \\
\text { barriers }\end{array}$ & 43 & 1 & 5 & 3.79 & 1.390 \\
\hline Lack of effective role formulators & 5 & 4 & 5 & 4.60 & .548 \\
\hline $\begin{array}{l}\text { Unclear regulation and executive } \\
\text { policies }\end{array}$ & 5 & 3 & 5 & 4.00 & 1.000 \\
\hline Unsuitable training system & 10 & 2 & 5 & 4.30 & .949 \\
\hline Lack of choice of real strategy & 8 & 1 & 5 & 3.63 & 1.302 \\
\hline Lack of a national attitude to strategy & 35 & 1 & 5 & 2.17 & 1.224 \\
\hline
\end{tabular}

Figure (3) and table (3) illustrates that, the most important issues which lead to faultier in strategic management implementation, in field of planning issue, in order are: "lack of identify the major problem and barriers", "Lack of strategic planning" and "time limitation.

Furthermore, according to figure eight, the strategy formulation (planning) is not determine, as a five most important factors of strategic management however, the time limitation is sixth most important factors, and strategy formulation is eighth most important factors thus it can be concluded that this three factors are prerequisite to have successful strategic management implementation, but they are not requisite to have successful strategic implementation in SMEs in the Iran.

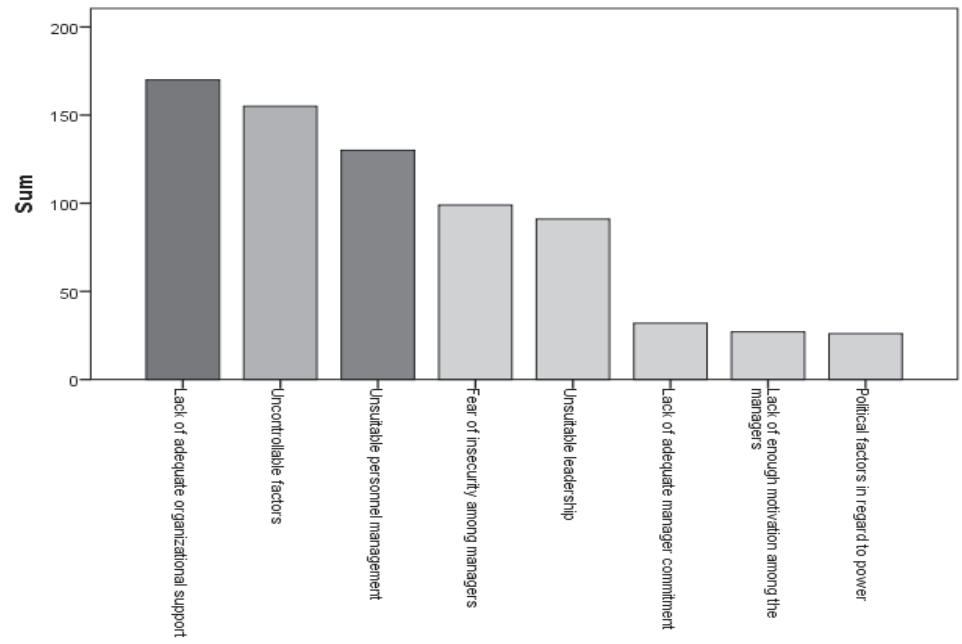

Figure 4 Barriers in field of Managerial 
Descriptive Statistics Q 10

\begin{tabular}{|l|c|c|c|c|c|}
\hline \multicolumn{7}{|c|}{ Descriptive Statistics } \\
\hline & $\mathrm{N}$ & Minimum & Maximum & Mean & Std. Deviation \\
\hline Unsuitable leadership & 41 & 1 & 5 & 2.22 & 1.541 \\
\hline $\begin{array}{l}\text { Lack of adequate organizational } \\
\text { support }\end{array}$ & 43 & 1 & 5 & 3.95 & 1.154 \\
\hline $\begin{array}{l}\text { Lack of adequate manager commit- } \\
\text { ment }\end{array}$ & 8 & 1 & 5 & 4.00 & 1.414 \\
\hline Fear of insecurity among managers & 44 & 1 & 5 & 2.25 & 1.102 \\
\hline Political factors in regard to power & 8 & 1 & 5 & 3.25 & 1.909 \\
\hline Unsuitable personnel management & 46 & 1 & 5 & 2.83 & 1.198 \\
\hline Uncontrollable factors & 47 & 1 & 5 & 3.30 & 1.020 \\
\hline $\begin{array}{l}\text { Lack of enough motivation among } \\
\text { the managers }\end{array}$ & 7 & 1 & 5 & 3.86 & 1.952 \\
\hline
\end{tabular}

Figure (4) and table (4) indicate that, the most important issues which lead to faultier in strategic management implementation, in field of planning respectively are, "Lack of adequate organizational support"," Uncontrollable factors" and "Unsuitable personnel management".

Moreover, by comparing question 8 with 10 it can be concluded, managerial issue is a Prerequisite issue to have successful strategic management implementation in SMEs in the Iran.

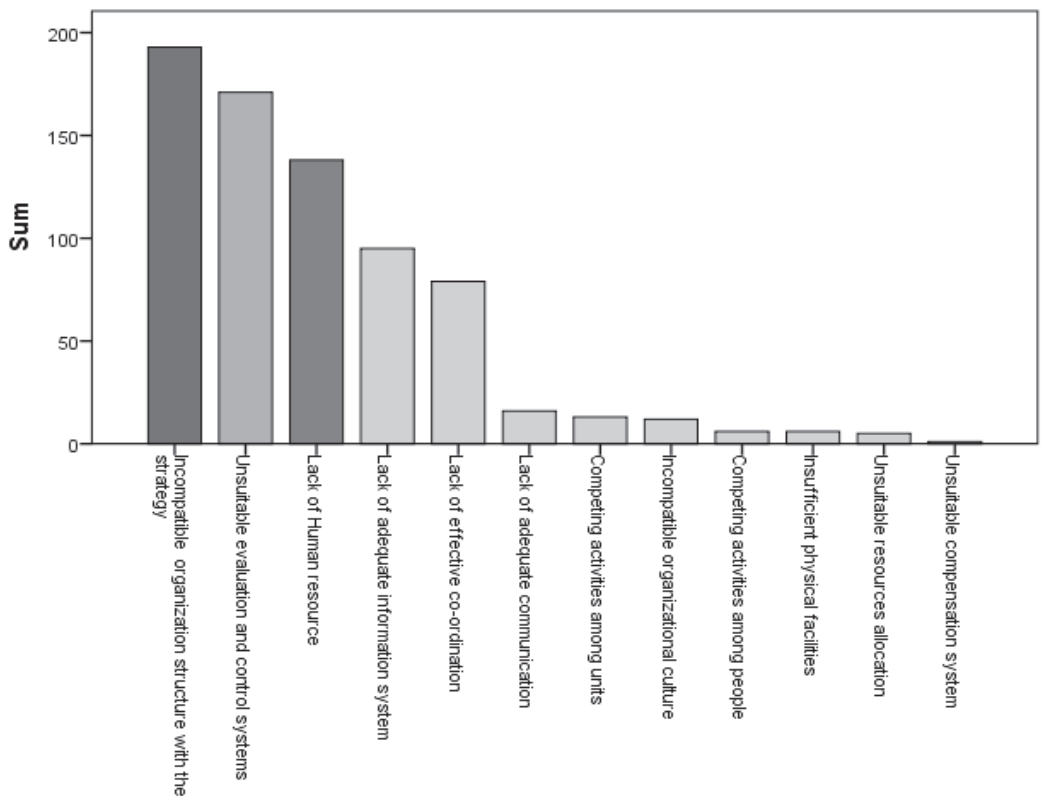

Figure 5 Barriers in field of Organization 
Descriptive Statistics of Barriers in field of Organization

\begin{tabular}{|c|c|c|c|c|c|}
\hline \multicolumn{6}{|c|}{ Descriptive Statistics } \\
\hline & $\mathrm{N}$ & Minimum & Maximum & Mean & Std. Deviation \\
\hline Lack of adequate information system & 44 & 1 & 5 & 2.16 & 1.119 \\
\hline Unsuitable resources allocation & 4 & 1 & 2 & 1.25 & .500 \\
\hline Lack of adequate communication & 5 & 1 & 5 & 3.20 & 2.049 \\
\hline Lack of effective co-ordination & 40 & 1 & 5 & 1.98 & 1.330 \\
\hline $\begin{array}{l}\text { Incompatible organization structure } \\
\text { with the strategy }\end{array}$ & 47 & 1 & 5 & 4.11 & 1.068 \\
\hline Incompatible organizational culture & 4 & 1 & 5 & 3.00 & 2.309 \\
\hline Competing activities among people & 3 & 1 & 4 & 2.00 & 1.732 \\
\hline Competing activities among units & 3 & 3 & 5 & 4.33 & 1.155 \\
\hline $\begin{array}{l}\text { Unsuitable evaluation and control } \\
\text { systems }\end{array}$ & 47 & 2 & 5 & 3.64 & .792 \\
\hline Unsuitable compensation system & 1 & 1 & 1 & 1.00 & . \\
\hline Insufficient physical facilities & 2 & 1 & 5 & 3.00 & 2.828 \\
\hline Lack of Human resource & 45 & 1 & 5 & 3.07 & 1.176 \\
\hline
\end{tabular}

As table (5) and figure (5) shows, "Incompatible organization structure with the strategy","Unsuitable evaluation and control systems" and "Lack of Human resources" are the main barriers in implementation of strategic management, in field of organization issue.

Moreover, by comparing question 8 with 11 it can be concluded, two of this three most popular barriers (problems) of implementation strategic management in SMEs in Iran are categorize as KSFs of strategic management implementation in SMEs in Iran as a result, this two factors ("evaluation and control" and "human resource") are requisite factor to have successful strategic management implementation in SMEs in the Iran. One the other word, without appropriate human resource and evaluation and control the enterprises is not able to have successful strategic management implementation.

Furthermore, figure (5) shows, Incompatible organization structure with the strategy is most important factors which lead to failure of strategic management implementation. Additionally, by comparing the outcome of this question with result of question 8 can be concluded that the organization structure is a prerequisite factor to have successful strategic management implementation. 


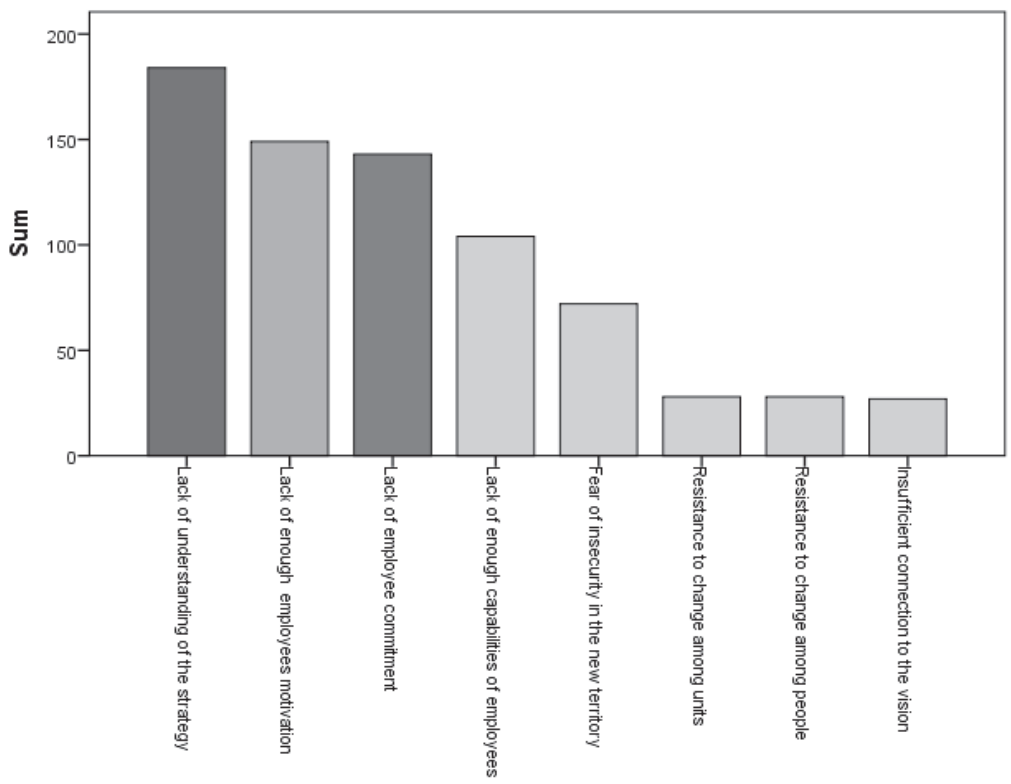

Figure 6 Barriers in field of Individual

Table 6

Descriptive Statistics Barriers in field of Individual

\begin{tabular}{|l|c|c|c|c|c|}
\hline \multicolumn{7}{|c|}{ Descriptive Statistics } \\
\hline & $\mathrm{N}$ & Minimum & Maximum & Mean & Std. Deviation \\
\hline Lack of employee commitment & 45 & 1 & 5 & 3.18 & 1.114 \\
\hline $\begin{array}{l}\text { Resistance to change among } \\
\text { people }\end{array}$ & 8 & 2 & 5 & 3.50 & 1.414 \\
\hline Resistance to change among units & 8 & 2 & 5 & 3.50 & 1.069 \\
\hline $\begin{array}{l}\text { Fear of insecurity in the new } \\
\text { territory }\end{array}$ & 41 & 1 & 5 & 1.76 & 1.300 \\
\hline $\begin{array}{l}\text { Lack of understanding of the } \\
\text { strategy }\end{array}$ & 45 & 1 & 5 & 4.09 & 1.164 \\
\hline $\begin{array}{l}\text { Insufficient connection to the } \\
\text { vision }\end{array}$ & 6 & 3 & 5 & 4.50 & .837 \\
\hline $\begin{array}{l}\text { Lack of enough capabilities of } \\
\text { employees }\end{array}$ & 46 & 1 & 5 & 2.26 & 1.124 \\
\hline $\begin{array}{l}\text { Lack of enough employees } \\
\text { motivation }\end{array}$ & 46 & 1 & 5 & 3.24 & 1.177 \\
\hline
\end{tabular}

Figure (6) illustrate that, the main barriers of SMEs in the Iran in order to practicing strategic management implementation in field of individual issue includes: "Lack of understanding of strategy", "Lack of enough employee motivation" and" lack of employee commitment". 
As a result of question seven (figure 6) the bottom line of organization hierarchy in SMEs in the Iran almost doesn't have any involvement in developing strategic management thus it can be consider that they don't have enough awareness about the organization strategic plan as a result this problem (barriers) can be consider as first sequence of this situation. Additionally, as subsequent, this situation can decrease the employee commitment in strategic management implementation which the result of question (12) proves these sequences.

Moreover, by comparison of question 12 and question 8 it can be concluded that motivation has a very critical role in order to have successful strategic management implementation in SMEs in the Iran because, in question 8 it classify as KSFs of SMEs in the Iran, also in question 12 it classify as major problem of SMEs in the Iran in field of individual issue. Thus, motivation is requisite factor to have successful strategic management implementation in SMEs in the Iran.

\section{PART TWO: QUALITATIVE ANALYSIS}

In general the result of interviews was the same as a result of quantitative data analysis however, the researcher identify that some of top-level management had confused in about "long term planning" phrase in strategic management definition. In this respect some of them define long term as five and more and some of them define it as a three years advance planning.

\section{Summary of findings}

In this respect, the researcher concludes from the results of questionnaire that, financial resource, environmental factors, monitoring and control, staff (human resources) and motivation of employee are the key success factors (KSFs) of strategic management implementation in SMEs in Iran.

\section{Managerial}

The outcomes of this research illustrates that Human resources plays a significant role in strategic management implementation as result, SMEs in Iran should try to provide any training that is required for application of strategic management.

SMEs in Iran should motivate their employees on more involvement in strategic management implementation, and it could happen if SMEs involve more employee and from all level of organization hierarchy in earlier stage of strategic management development.

To sum up, all of these results indicate that, those companies which want to apply strategic management should have enough attention on Strategic Human Resources management (SHRM) as a one of the critical factors.

Data analysis classifies the commitment of employee as one of the barriers to implement strategic management in SMEs in Iran. Thus SMEs in Iran should have program to increase employee commitment, such as, set up learning and training program, provide fair and competitive salary and make sure the employees know they are valued for organization.

The outcomes that have discussed in the result and discussion chapter indicate, organization structure is one of the main issues of strategic management implementation. Thus, SMEs in Iran should be considering these factors when they want to develop strategic management or strategy formulation. 
The result of research proves the importance of environmental factors in order to have successful strategic management implementation, furthermore as a result of industry analysis; Iran has been classified as unsustainable business environment thus the SMEs in Iran must formulate their strategy with high caution index.

The outcomes that have discussed in the result and discussion chapter indicate, the unsuitable evaluation and control system as one of the barriers thus the SMEs in Iran must provide appropriate control and evaluation system while developing strategic management.

As a result of this research, majority of SMEs in Iran do not have specific department in order to develop strategic management. In this respect SMEs should indicate department or area which is responsible for developing strategic management to make responsibility clear and prevent any inter- organizational conflicts.

\section{RECOMMENDATIONS FOR FUTURE WORK}

Future research could attempt to modeling process which reducing the factors which leading to failure in strategic management implementation. Also there is not any particular module for practicing strategic management in SMEs thus it could be consider as future work in this field.

\section{REFERENCES}

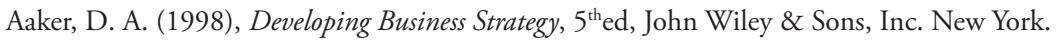

Alashloo, F. R., Castka, P., Sharp, J. M. (2005), Towards Understanding the Impeders of Strategy Implementation in Higher Education (HE): A case of HE Institutes in Iran, Quality Assurance in Education, 13(2), pp. 132-147.

Birnbaum, B. (2009), Strategy Implementation: Six Supporting Factors, available online.

Bryman, A., Bell, E. (2007), Business Research Methods, 2nd ed. USA: Oxford University Press, p. 12.

Bryson, J. \& Bromiley, P. (1993), Critical factors affecting the planning and implementation of major projects, Strategic Management Journal, 14(2), pp. 319-337.

Bryson, J. \& Bromiley, P. (1993), Critical factors affecting the planning and implementation of major.

Bryson, J. M. (1995), Strategic Planning for Public and Nonprofit Organizations, Jossey-Bass Publishers, San Francisco, CA.

Cespedes, Frank, V. (1991), Organizing and Implementing the Marketing Effort, Reading, MA: Addison-Wesley Publishing Company.

Christopher Stoney (2001), Strategic management or strategic Taylorism?: A case study into change within a UK local authority, International Journal of Public Sector Management, Vol. 14, Iss: 1, pp. $27-42$.

Coline White (2004), Strategic Management, London: Macmillan, 5.

David, F. (2005), Strategic Management, Prentice-Hall Publishing. Upper Saddle River, NJ.

David, F. R. (1989), Strategic Management, New Jersey: Prentice-Hall.

Don Hofstrand (2007), Strategic planning for value-added farm businesses, Available:http://www.agmrc.org/business_development/strategy_and_analysis/articles/strategic_planning_for_valueadded_farm_businesses.cfm. Last accessed 2012.

Floyd, S. W. and Woolridge, B. (1992), Managing Strategic Consensus: The Function of Effective Implementation, Academy of Management Excutives, 6, pp. 27-40.

Gazda, J. (2010), Real Business Cycle - Methodology and Tools, Economics \& Sociology, Vol. 3, No. 1, pp. 42-48.

Higgins, J. M. and Vincze, J. W. (1989), Strategic Management: Text and Cases, New York, NY: The Dryden Press. 
Higgins, J. M. (2005), The eight 'S's of successful strategy execution, Journal of Change Management, 5(1), pp. 3-13. John A., Parnell (2005), Strategic Management: Theory and Practice, London: SAGE Publications, 45.

Joyce, P. \& Woods, A. (2003), Managing for growth: decision making, planning, and making changes, Journal of Small Business and Enterprise Development, 10 (2), pp. 144-151.

Lingle, J. \& Schieman, W. (1994), Is data scatter subverting your strategy, Management Review, 83(5), pp. 53-56.

Okumus, F. (2001), Towards a Strategy Implementation Framework, International Journal of Contemporary Hospitality Management, 13(7), pp. 327-338.

Parnell, J. A. (2005), Strategic philosophy and management level, Management Decision, Vol. 43, No. 2, pp. 157-70.

Porter, M. E. (1985), Competitive Advantage: Creating and Sustaining Superior Performance, the Free Press, New York, NY. 23.

Roth, K., Schweiger, M. \& Morrison, J. (1991), Global strategy implementation at unit level: operational capabilities and administrative mechanisms, Journal of International Business Studies, 22(3), pp. 369-402.

Skivington, E. J. \& Daft, L. R. (1991), A study of organizational framework and process modalities for the implementation of business level strategic decisions, Journal of Management Studies, 28(1), pp. 45-68.

Srivastava (2011), Business Research Methodology, India: Tata McGraw-Hill, Chapter 6.

Stevens. R. E., Wrenn, W. B., Sherwood, P., Ruddick, M. (2006), The Marketing Research Guide, 2nd ed. USA: Best Business Book.

Wheelen Thomas L., Hunger, J. D. (2008), Strategic Management Business policy, 11th edn. New Jersey: Pearson international edition.

Williams, R., Bertsch, B., Dale, B., van der Wiele, T., van Iwaarden, J., Smith, M., Visser, R. (2006), Quality and risk management: what are the key issues? The TQM Magazine, Vol. 18, Iss: 1, pp. 67-86.

Wilson Jonathan (2010), Essential of Business Research, London, United Kingdom: Sage Publications, pp. 3, 34.

Wilson, I., Essien, B. (2012), Strategic Management, Author House, USA, p. 291.

www.birnbaumassociates.com/strategy-implementation.htm, 2012.2.14

Yip, O. S. (1992), Total Global Strategy, London: Prentice-Hall. 